\title{
OS CANTARES DE WHITMAN E NERUDA: $A$ TRADIÇÃO DO ÉPICO-LÍRICO AMERICANO
}

The poetic expression of Whitman and Neruda: the American epic-liric tradition

Luci M. Collin Lavalle*

\section{A} presente discussão da relação entre a poesia de Walt Whitman e a poesia de Pablo Neruda começa com um levantamento da importância de Whitman no cenário geral da expressão poética, e com uma breve caracterização da diç̧ão whitmaniana.

A poesia norte-americana do século XIX traz sempre em destaque o nome de Walt Whitman (1819-1892) que, ao longo do tempo, se tornou internacionalmente reconhecido. Inspirada pelo conteúdo da poesia de Whitman, a crítica acabou criando uma série de epítetos para caracterizá-lo: "Poeta da Democracia", "Poeta da Ciência", "Poeta da Religião", "Poeta Místico", "Poeta Materialista"; contudo, vale dizer, nenhum deles representa a poesia de Whitman em sua totalidade - uma poesia múltipla e que consegue comportar, ao mesmo tempo, o que sugerem todos os epítetos acima.

Alguns leitores, hoje, tendem a valorizar Whitman apenas como aquela figura rebelde e de ideais democráticos que influenciou a Beat Generation. Entretanto, uma investigação mais cuidadosa acerca do papel histórico deste poeta, enquanto precursor da expressão literária moderna, revela que grandes

* Universidade Federal do Paraná 
LAVALLE, L. C. Os cantares de Whitman e Neruda: a tradição...

representantes da poesia mundial - T. S. Eliot, W. Stevens, H. Crane, D. H. Lawrence, E. Pound, W. C. Williams, J. Ashbery, F. Pessoa, J. L. Borges, F. Garcia Lorca, R. Dario, entre outros - são descendentes, em "aspiração e postura", de Whitman. Na verdade, podemos melhor dimensionar a importância de Whitman não só apontando estes renomados "descendentes", mas também investigando a situação da poesia nos EUA antes do aparecimento de Whitman. Para tal, remontamos a um importante marco na história da literatura norte-americana - o ensaio O poeta, do filósofo e escritor Ralph Waldo Emerson, publicado em 1844. Nesse ensaio Emerson diz:

...o poeta é um representante: o símbolo, dentre os homens incompletos, do homem completo, informando-nos não de sua própria riqueza, mas da riqueza comum a todos. (...) é o homem sem impedimentos, que entrevê e pratica aquilo com que os outros sonham, que atravessa toda a escala da experiência; ele é o representante dos homens, porque tem a mais alta capacidade de receber e de transmitir. (...) $\mathrm{O}$ emblema e as credenciais do poeta são o fato de ele anunciar o que ninguém havia profetizado. Ele é o verdadeiro e único terapeuta; ele sabe e diz; somente ele revela algo novo, pois presenciou e conheceu os fenômenos que descreve. (...) Os poetas são, por conseguinte, deuses libertadores (...) eles são livres e nos tornam livres. (CHIAMPI, 1991, p. 72-80)

E Emerson conclui num tom que revela um quê de decepção: "Procuro em vão o poeta que descrevo. Não nos dirigimos, com simplicidade ou profundeza suficientes, à vida, nem ousamos decantar nossa própria era e condições sociais (...) Ainda não temos nenhum gênio na América (...) E no entanto a América é um poema diante de nossos olhos" (CHIAMPI, 1991, p. 81-82). Vemos então que, para Emerson, o potencial para a existência de grandes poetas norte-americanos já existia não tendo ainda o país, contudo, produzido alguém que, em sua poesia, focalizando a experiência real do povo, desse início a uma tradição poética genuinamente norte-americana.

Uma década depois do ensaio $O$ poeta, Emerson finalmente identifica o poeta por quem esperava para assumir a posição de "deus libertador". Em 1855, após ler o Leaves of grass, Emerson escreveu uma carta a Walt Whitman comentando o livro: "I find it the most extraordinary piece of wit and wisdom that America has just contributed" (MILLER, 1957, p. 367). 
Leaves of grass é um único poema. Whitman devotou quase 40 anos à conclusão dessa obra que cresceu de um modesto volume de pouco mais de 100 páginas (publicado em 1885, com 13 poemas sem título) a uma coleção de dois volumes com mais de 450 páginas (edição final em 1891-1892, com 423 subpoemas agrupados em 16 seções principais).

A originalidade de Whitman está em sua inventividade mitológica, no extraordinário domínio da linguagem figurativa, do verso livre e das inovações rítmicas. O uso de técnicas experimentais por Whitman funcionou como exemplo aos novos poetas; como coloca Perkins (1990, p. 905):

\begin{abstract}
...Whitman's free verse provided an example that slowly communicated itself to later poets who likewise sought to refresh their art. His use of rhythm as a fluid instrument of verse demonstrated a range of possibilities beyond that of conventional meter. He wrote symphonically, associating themes and melodies with great freedom, and suggestiveness; he abandoned conventional and hackneyed poetic figures and drew his symbolism freshly from experience.
\end{abstract}

Com sua poesia de evocação messiânica, Whitman tornou-se o "xamã americano", aquele profeta religioso que, com uma profunda ligação com o divino, traz uma mensagem de libertação. Como bardo solitário que proclama ser a multidão, Whitman levanta uma mitologia essencial que não é apenas resultado do passado norte-americano, mas que também deriva de sua própria experiência pessoal, uma experiência que é “...lived or dreamed, and his hero is, therefore, himself. $\mathrm{He}$ is, in his sense, the first truly modern poet with epic ambitions, the first author to portray himself as the mythic representative of his people and his time." (FIEDLER, 1963, p. 14).

Entre os temas que Whitman explorou estão o humanismo, a celebração e a angústia (ou a auto-celebração e a auto-angústia sob formas de "elegias ao eu"), o antiescravagismo, a denúncia aos baixos salários e às arbitrariedades político-sociais (marcando os direitos da mulher e dos trabalhadores), o apelo à democracia e ao patriotismo, a aversão às guerras e, por fim, a valorização da liberdade do espírito pelo reconhecimento das prioridades da vida. Seus poemas, impregnados de exaltação panteísta, clamam por uma comunhão ideal com "o outro", que geralmente é representado pelo homem comum (o camarada), ou que 
LAVALLE, L. C. Os cantares de Whitman e Neruda: a tradição...

é, às vezes, o Deus dos transcendentalistas (a oversoul) manifestado na Natureza. Abaixo, à guisa de ilustração, um fragmento do Canto do universal de Whitman:

3.

E tu, América,

Para a culminação do plano, sua idéia e sua realidade,

Para isso (e não para ti mesma) tu chegaste.

Também tu abranges tudo,

Abraçando, levando, acolhendo tudo, tu também, por largos e novos caminhos,

Diriges-te para o ideal.

As fés comedidas de outras terras, as grandezas do passado, Não são para ti, mas tuas próprias grandezas,

Mas fés e amplitudes divinizantes, absorvendo, compreendendo tudo, Tudo podendo ser escolhido por todos.

Tudo, tudo para a imortalidade,

$\mathrm{O}$ amor como a luz silenciosamente envolvendo tudo,

$\mathrm{O}$ aperfeiçoamento da natureza abençoando tudo,

As flores, os frutos das idades, pomares divinos e certos,

Formas, objetos, crescimentos, humanidades, amadurecendo em imagens espirituais. ${ }^{1}$

Em seu conhecido livro $O$ cânone ocidental, Harold Bloom agrupou J. L. Borges, P. Neruda e F. Pessoa argumentando que a literatura desses autores circula em torno de um "Whitman Hispano-Português". Mesmo considerando poetas norte-americanos da estatura de W. Stevens e H. Crane, Bloom aponta Neruda como o mais autêntico herdeiro de Whitman e acrescenta que, para Neruda, o bardo norte-americano era "um pai idealizado" (BLOOM, 1995, p. 459) que o ajudou a ver a realidade das Américas sem a influência da realidade do Velho Mundo, que o levou a compreender a expressão e a consciência do Novo Mundo vendo a si mesmo, a América Latina, sua geografia, flora, fauna e povo.

1 DEUTSCH (1965, p. 219-221); tradução de: Brenno Silveira e Péricles Eugênio da Silva Ramos. 
A proximidade entre Whitman e Neruda fica mais interessante quando examinamos afirmações que a reforçam dentro da própria obra do poeta chileno. Em Venho renegociar minha divida com Walt Whitman, discurso pronunciado em New York, no Pen Clube dos EUA, em abril de 1971, NERUDA (1993, p. 747) diz:

Por mi parte, yo, que tengo ahora cerca de 70 años, descubrí a Walt Whitman cuando tenía solo 15, y lo consideré mi más grande acreedor. Estoy ante vosotros, sintiendo que le guardo para siempre la más grande y maravillosa deuda que me ha ayudado a existir. Para renegociar esta deuda debo partir reconociendo su existencia, y reconociéndome como el humilde siervo de um poeta que abarcó la tierra com sus zancadas largas y lentas, deteniéndose en cualquier parte para amar, para estudiar, para aprender, para enseñar, para admirar. El hecho es que este gran hombre, este moralista lírico, eligió una difícil senda para él: fue tanto um cantor didáctico como torrencial, cualidades que parecen oponerse, y ser más apropiadas para un líder que para um escritor. Pero lo que realmente cuenta es que Walt Whitman no tuvo miedo de enseñar lo que significa aprender a través de la vida y asumir la responsabilidad de traspassar la lección.

Considerações sobre Walt Whitman feitas por Pablo Neruda aparecem também em Confesso que vivi:

Se a minha poesia tem algum significado, é o dessa tendência espacial, ilimitada, que não se satisfaz num compartimento. A minha fronteira tinha de a saltar eu mesmo, não a tracei nos bastidores de uma cultura distante. Tinha de ser eu mesmo, esforçando-me por me dilatar como as próprias terras onde me coube nascer. Outro poeta deste continente ajudou-me em tal caminho. Refiro-me a Walt Whitman, meu companheiro de Manhattan. (NERUDA, 2000, p. 81).

Para Neruda, Whitman nunca temeu ser nem moralista nem imoral; ele foi o primeiro poeta com visão total e ampla das relações entre homens e nações, com uma poesia nacionalista que é parte de uma visão universal total e orgânica. Neruda vê Whitman como "el primer hombre de la historia em hablar con auténtica 
LAVALLE, L. C. Os cantares de Whitman e Neruda: a tradição...

voz americana continental, en sustentar um auténtico nombre americano" (NERUDA, 1993, p. 748, v. 3), denuncia o individualismo extremo da maioria dos escritores, enfatiza que seria uma grande vitória se todos pudessem caminhar juntos vencendo fronteiras poéticas, lingüísticas e raciais, e rende justa homenagem àqueles que, como Whitman, "han hecho possible a los escritores de todos los países experimetar la sensación de sentirse únicos, sin renunciar a sus próprias tendências o creencias." (NERUDA, 1993, p. 750, v. 3).

Em relação a exemplos pontuais de referências a Whitman na poesia de Neruda destacamos dois: o primeiro deles é a Oda a Walt Whitman escrita em 1954 (NERUDA, 1993, p. 363-367, v. 2):

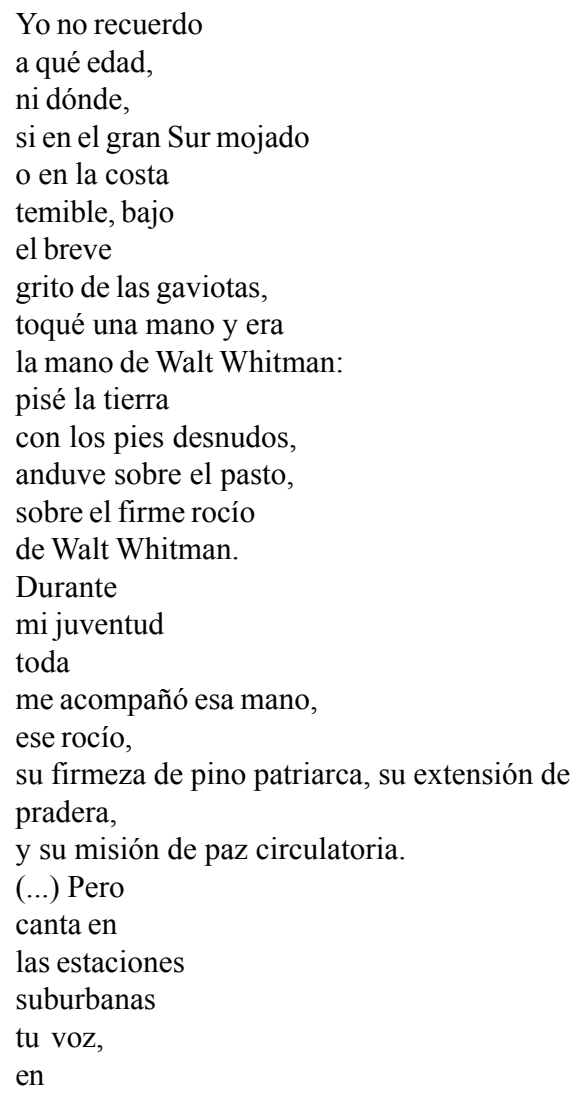


LAVALLE, L. C. Os cantares de Whitman e Neruda: a tradição...

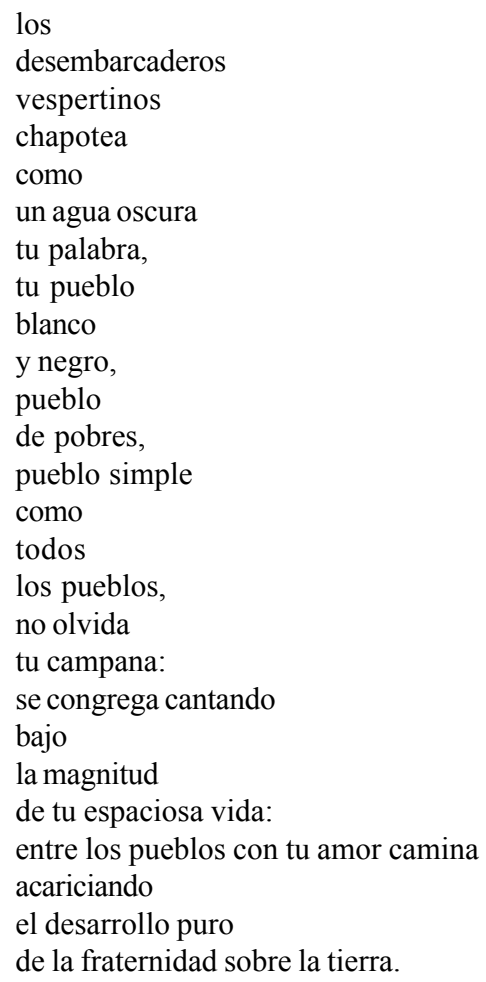

Já o segundo exemplo de menção direta a Whitman por Neruda é extraído de Incitação ao nixonicídio e louvor da Revolução Chilena (1973), no poema Começo por invocar Walt Whitman, onde Neruda (1980, p. 6) investe contra "o delirante genocida" Nixon, recorrendo à poesia como arma de ataque ao inimigo, usando a força do "poema guerreiro":

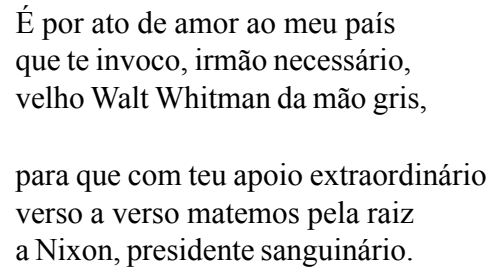


LAVALLE, L. C. Os cantares de Whitman e Neruda: a tradição...

Pedindo ao velho bardo que me invista, assumo meus deveres de poeta armado do soneto terrorista.

Ainda não se pode observar uma influência maciça de Whitman sobre Neruda em Crepusculário (1923), nem em Tentativa do homem infinito (1925), nem nos Vinte poemas de amor e uma canção desesperada (1924). Contudo, já se nota que em alguns poemas destes livros a atmosfera pessimista e impressionista usual é abandonada, e Neruda entoa hinos de alegria juvenil em contato com a beleza dinâmica de sua terra, com um "regionalismo filosófico" cheio de identificações panteístas com a Natureza.

Os primeiros pontos nítidos entre Whitman e Neruda aparecem em Residência na terra (1931) e Canto geral (1950), tanto em relação ao estilo quanto às temáticas. Ambos os livros são marcados pela tendência sensualista. No Canto geral temos evocações da juventude, um profundo e deliberado dinamismo, a fé no homem e nos valores essenciais da ação coletiva em metáforas à natureza americana que visam conduzir à descoberta da unidade entre o homem e a paisagem que o cerca. A proximidade com Whitman é mais sensível - Whitman humaniza a natureza e se identifica com ela dentro do plano orgânico transcendental. Neruda, por sua vez, exalta a natureza e nela reconhece o objeto amoroso do homem americano que a conquista em uma luta épica. Da mesma forma que Whitman, Neruda escreve o Canto geral a fim de construir uma obra fundamental para a sociedade em que vive, como coloca Allegrezza (2003, p. 13):

Also, as with Whitman, Neruda believes in the persuasive function of poetry in creating a political culture necessary for a political institution. In Neruda's case, however, poetry comes before the establishment of the political reversal. A democracy was already in place for Whitman. Canto general is as much a founding text of Latin America as it is a call for communism in the continent. Whereas Whitman rewrites history in Leaves of Grass to support the progress of democracy in the West, Neruda rewrites history to show the inevitable progress of communism. For Neruda, his epic poem must help create the cultural and political environment through which the despots of Latin America will be deposed in favor of communism. 
Em termos de forma, Whitman se deu conta que o épico convencional era artificial aos seu propósitos e criou uma nova forma em Leaves of grass: o épicolírico. Neruda adotou essa forma como uma expressão literária autêntica das Américas e usou o Leaves of grass como modelo par ao Canto geral. Como Whitman, Neruda usa as técnicas tradicionais do épico (como a invocação, o tom bárdico, os ritmos bíblicos, a catalogação, a estrutura episódica); eles também se aproximam no uso do verso livre, do gerúndio, do emprego de termos do vocabulário dos trabalhadores e da enumeração detalhada e específica que em Whitman é um processo de recriação do objeto, e em Neruda é um ensaio de imagens, metáforas e nomes que exacerba o efeito de acumulação.

Em termos de conteúdo, vemos que o leitmotif do sentimento de camaradagem proletária e a glorificação da solidariedade aparece em Neruda como eco da poesia social de Whitman. Como em Leaves of grass, o sentido de camaradagem é a idéia central do Canto geral. A intenção de Neruda é reforçar uma camaradagem entre os povos da América Latina, revelando as qualidades do povo ao próprio povo, e levando a uma libertação do sistema capitalista. A fé universalista de Leaves of grass se aproxima do internacionalismo do Canto geral. Neruda parte do conceito de democracia, rejeita o capitalismo e evolui para o comunismo que seria, em seu modo de ver, a forma de governo do povo pelo povo. Os dois poetas falam às multidões com o sonho - poético e histórico - da democracia, mas também com um certo hermetismo advindo da complexidade poética e psicológica de suas obras. ${ }^{2}$

Embora as premissas das mensagens de alento universalista e de amor ao continente americano de Whitman e de Neruda e seus estilos sejam bastante próximos, cumpre agora também apontar as diferenças ideológicas essenciais de ambos os poetas. Em termos de estilo, Neruda naturalmente absorveu elementos poéticos da literatura experimentalista no início do século XX e tem, portanto, uma composição poética tecnicamente mais sofisticada do que Whitman. Em termos de conteúdo, há uma diferença básica entre eles: Whitman é o poeta místico e panteísta - há para ele uma projeção metafísica em cada aspecto do mundo e da vida que ele exalta o tempo todo em sua obra, o

2 No poema Que despierte el leñador (NERUDA, 1993, p. 572-575, v. 1) podemos notar o estilo enumerativo de Whitman na descrição da civilização mecânica e industrial dos EUA, a riqueza agrícola e a grandeza moral e física dos trabalhadores da cidade, dos portos, do campo, brancos e negros. Nesse poema, Neruda também descreve as impressões de um soldado norte-americano ao voltar da guerra (em certo sentido, próximo ao poema Democratic Vistas de Whitman) e denuncia a corrupção política do governo. Neruda expressa a esperança de que um novo Abraham Lincoln, o lenhador, surgirá do povo para salvar os EUA. Também na segunda parte do Canto geral, a seqüência de 12 cantos intitulada As alturas de Macchu Picchu revela a influência de Whitman pelo humanismo e sensualidade que apresenta, na voz do poeta consciente da dimensão humana, que se apresenta como um redentor. 
"americano" em Whitman simboliza o homem superior e a sua América representa o ideal da sociedade perfeita a surgir no futuro através do progresso material e espiritual; já Neruda é, pelo menos em boa parte de sua produção poética, engajado politicamente - ele é materialista e sua identificação com a América passa principalmente pela preocupação política e social. Como afirma Allegrezza (2003, p. 142):

In attempting to call the people together, Neruda has a different project than Whitman had. For Whitman, a democracy was already in place; thus, Whitman primarily wants to see that the democracy retains its pure elements, so he creates a democratic personality paradigm. Neruda knew Whitman's ideas of creating a governmental culture; however, Neruda needed his poetry first to instigate a communist change in the government. After the change, he hoped that the primary ideas in Canto general would help to create a communist culture. While Whitman stresses camaraderie in the abstract as love for one's fellow citizens, Neruda often expresses his ideas of camaraderie through practical needs. For example, one leitmotif in the work is bread. Moreover, unlike Whitman who is motivated by the fear of governmental failure, Neruda is galvanized by seeing the suffering of those around him. His politicization occurred primarily after his experience in Spain where the sight of human misery forced him to connect poetry and politics. It is this connection that he brought back to Chile.

Neruda queria compor uma obra épica que fundasse uma nova tradição, que unisse os latinos e, fazendo-os compreender o valor de uma "cultura política", os conduzisse a um futuro melhor. E o que Whitman havia proposto ficou muito próximo ao que Neruda procurou: escrever livros que funcionassem como "cadernos poéticos" aplicados à formação de uma cultura democrática. Nessa busca, ambos exploraram o épico-lírico como uma nova forma para a expressão de uma nova cultura, que pudesse ajudar os americanos construir o ideal da América unida. Assim, o Leaves of grass e o Canto geral têm a mesma estatura como obras fundamentais, organicamente ligadas às novas perspectivas sociais. Whitman e Neruda são fundadores e expressões máximas de uma tradição literária que se solidifica no épico-lírico americano e, apesar de suas pequenas diferenças políticas, filosóficas e literárias, ambos se inspiram num autêntico amor ao homem e à vida. 


\title{
RESUMO
}

Focalizando a obra do poeta norte-americano Walt Whitman e a obra do poeta chileno Pablo Neruda, o ensaio discute a gênese e o desenvolvimento do épico-lírico americano, a partir do levantamento de similaridades e de contrastes formais e temáticos entre ambas as produções poéticas.

Palavras-chave: Whitman e Neruda, poesia épico-lírica, poesia social.

\begin{abstract}
By focusing on the work of the North-American poet Walt Whitman and the work of the Chilean poet Pablo Neruda, the essay discusses the genesis and the development of the American epic-lyric, taking into account formal and thematic similarities and contrasts between both poetic productions.

Key-words: Whitman and Neruda, epic-lyric poetry, social poetry.
\end{abstract}

\section{REFERÊNCIAS}

ALlEGREZZA, W. Politicizing the reader in the American Lyric-Epic: Walt Whitman's Leaves of Grass and Pablo Neruda's Canto General. Dissertation (PhD) - ETD - 12913145352-2003.

BLOOM, H. O cânone ocidental. Rio de Janeiro: Objetiva, 1995.

CHIAMPI, I. (Coord.). Fundadores da modernidade. São Paulo: Ática, 1991.

DEUTSCH, B. Walt Whitman. Tradução de: Brenno Silveira e Péricles Eugênio da Silva Ramos. São Paulo: Martins. 1965.

FIEDLER, L. (Org.). Whitman - selected poems from Leaves of Grass. New York: Dell Publishing, 1963.

MILLER, P. (Ed.). The American Transcendentalists. New York: Doubleday, 1957.

NERUDA, P. Confesso que vivi. Rio de Janeiro: Bertrand Brasil, 2000.

. Antologia Breve. Tradução e seleção de: Fernando Assis Pacheco. 6. ed. Lisboa: Dom Quixote, 1999.

Obras completas. Buenos Aires: Losada, 1993. v. 2 e 3. 
LAVALLE, L. C. Os cantares de Whitman e Neruda: a tradição...

. Canto geral. Tradução de: Paulo Mendes Campos. 5. ed. São Paulo: DIFEL, 1982. Incitação ao Nixonicídio e louvor da revolução chilena. Tradução de: Olga

Savary. Rio de Janeiro: Francisco Alves, 1980.

PERKINS, G. (Ed.). The American tradition in literature. 7. ed. New York: McGraw-Hill, 1990. 